\title{
Papers
}

\section{Babies sleeping with parents: case-control study of factors influencing the risk of the sudden infant death syndrome}

\author{
Peter S Blair, Peter J Fleming, Iain J Smith, Martin Ward Platt, Jeanine Young, Pam Nadin, P J Berry, \\ Jean Golding, and the CESDI SUDI research group
}

\begin{abstract}
Objective To investigate the risks of the sudden infant death syndrome and factors that may contribute to unsafe sleeping environments.

Design Three year, population based case-control study. Parental interviews were conducted for each sudden infant death and for four controls matched for age, locality, and time of sleep.

Setting Five regions in England with a total population of over 17 million people.

Subjects 325 babies who died and 1300 control infants.

Results In the multivariate analysis infants who shared their parents' bed and were then put back in their own cot had no increased risk (odds ratio 0.67; $95 \%$ confidence interval 0.22 to 2.00 ). There was an increased risk for infants who shared the bed for the whole sleep or were taken to and found in the parental bed (9.78; 4.02 to 23.83), infants who slept in a separate room from their parents $(10.49 ; 4.26$ to $25.81)$, and infants who shared a sofa $(48.99 ; 5.04$ to 475.60). The risk associated with being found in the parental bed was not significant for older infants ( $>14$ weeks) or for infants of parents who did not smoke and became non-significant after adjustment for recent maternal alcohol consumption ( $>2$ units), use of duvets ( $>4$ togs), parental tiredness (infant slept $\leqslant 4$ hours for longest sleep in previous 24 hours), and overcrowded housing conditions ( $>2$ people per room of the house).

Conclusions There are certain circumstances when bed sharing should be avoided, particularly for infants under four months old. Parents sleeping on a sofa with infants should always be avoided. There is no evidence that bed sharing is hazardous for infants of parents who do not smoke.
\end{abstract}

\section{Introduction}

In most non-westernised cultures the mother commonly shares a bed with her infant. ${ }^{1}$ Postulated physiological benefits of close contact between infants and care givers include improved cardiorespiratory stability and oxygenation, fewer episodes of crying, better thermoregulation, an increased prevalence and duration of breast feeding, and enhanced milk production. $^{23}$
Before the reduction in the rate of the sudden infant death syndrome there was conflicting evidence on the effect of bed sharing. ${ }^{4-6}$ Early observational studies suggested parental alcohol consumption, drug ingestion, obesity, and fatigue to support the concept that parents may lie on an infant who shares the bed with them. ${ }^{7-9}$ Data from New Zealand implicated bed sharing as a risk factor for sudden infant death. ${ }^{10}$

The importance of socioeconomic deprivation and bed sharing has been highlighted in New Zealand among the Maori population, ${ }^{11}$ which has high rates of smoking and alcohol consumption, and in the United States among poor black populations. ${ }^{12}$ In certain Asian cultures, however, where particular forms of mother-infant cosleeping are common such as in Japan $^{13}$ and Hong Kong, ${ }^{14}$ the rates of cot death are low, corresponding to findings in the Bangladeshi ${ }^{15}$ and Asian ${ }^{16}$ communities in the United Kingdom and the Pacific Island communities in New Zealand. ${ }^{17}$

While the benefits of the supine sleeping position for infants are now clear, there is no consensus on where the infant should sleep in relation to the parents. The study of sudden unexpected deaths in infancy (part of the confidential inquiry into stillbirths and deaths in infancy: CESDI SUDI study) is the first to be conducted after the fall in the rate of cot death in the United Kingdom and was specifically designed to identify whether known risk factors had changed or new factors had emerged.

We investigated the risks associated with different sleeping environments and how factors relating to parenting practice, both routine and specific, affect the infant.

\section{Methods}

The methodological detail of the study and sociodemographic details have been fully described elsewhere $^{18}$ and the results from the first two years published. ${ }^{19}$ Briefly, it was a large population based casecontrol study initially conducted in three former health regions (South West, Northern, and Yorkshire) for two years (February 1993 to January 1995) and expanded (Wessex and Northern regions) for a third year (April 1995 to March 1996). The study aimed to include all cases of sudden unexpected deaths of infants aged 7 to 364 days from a total study population of 17.7 million.

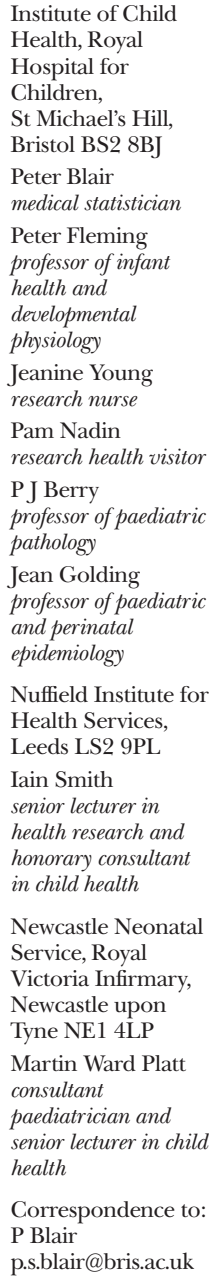

Nuffield Institute for Health Services, Leeds LS2 9PL

Iain Smith

senior lecturer in

health research and

honorary consultant in child health

Newcastle Neonatal Service, Royal Victoria Infirmary, Newcastle upon

Tyne NE1 4LP

Martin Ward Platt consultant

paediatrician and

senior lecturer in child

health

Correspondence to: P Blair p.s.blair@bris.ac.uk

BMJ 1999;319:1457-62 
Data were collected on a questionnaire by research interviewers and from medical records. Bereaved families were visited within days of the death for a narrative account and again within two weeks to complete the questionnaire. Four controls for each case were selected. The health visitor for the infant who died was asked to identify two babies on her case list born in the two weeks before the index baby and two babies born in the two weeks after the index baby. In the few instances when the family identified was not available or declined to be interviewed or when the health visitor thought inclusion inappropriate-for example, because of recent bereavement - then the family with the baby next closest in age was substituted. The interviewer visited each control family within a week of the index death to collect the same data as for the index case. A period of sleep (the "reference sleep") was identified in the control infant's life in the 24 hours before the interview corresponding to the time of day during which the index baby had died. The questionnaire included a total of over 600 fields, including demographic and social data; the medical history of the infant and other family members; use of cigarettes, alcohol, and drugs; the precise sleeping arrangements for the infant; and full details of the events preceding and the circumstances surrounding the death (or relevant sleep).

Cause of death was established by a multidisciplinary committee after a full paediatric necropsy to a standard protocol was performed. All deaths were classified according to the Avon clinicopathological system. ${ }^{18}$

\section{Statistical methods}

Data that were not normally distributed were described by using medians and interquartile ranges. Odds ratios, $95 \%$ confidence intervals, and $\mathrm{P}$ values for the univariate and multivariate analysis were calculated, taking into account matching with conditional logistic regression by using the statistical package sas. $^{20}$ The age of the control infant was taken as the age at the ref-

Table 1 Infant's sleeping environment* in relation to parents: usual night time practice and socioeconomic breakdown. Figures are numbers (percentage) of babies

\begin{tabular}{|c|c|c|c|}
\hline Detail & Babies who died & Controls & Univariate odds ratio† $(95 \% \mathrm{Cl})$ \\
\hline \multicolumn{4}{|c|}{ All socioeconomic classesł } \\
\hline No of babies & $320 \S$ & $1299 \S$ & \\
\hline Usual room sharer & $189(59.1)$ & $813(62.6)$ & 1.00 \\
\hline Usual solitary sleeper & $77(24.1)$ & $410(31.6)$ & 0.88 (0.62 to 1.25$)$ \\
\hline Usual bed sharer & $54(16.9)$ & $76(5.90)$ & 2.99 (1.94 to 4.63$)$ \\
\hline \multicolumn{4}{|c|}{ Socioeconomic classes I, II, III non-manualł } \\
\hline No of babies & 1289 & 8509 & \\
\hline Usual room sharer & $69(53.9)$ & $497(58.5)$ & 1.00 \\
\hline Usual solitary sleeper & $42(32.8)$ & $312(36.7)$ & 1.33 (0.78 to 2.27) \\
\hline Usual bed sharer & $17(13.3)$ & $41(4.8)$ & 4.07 (1.75 to 9.46$)$ \\
\hline \multicolumn{4}{|c|}{ Socioeconomic classes III manual, IV, V, and unemployedł } \\
\hline No of babies & 1909 & 4469 & \\
\hline Usual room sharer & $118(62.1)$ & $315(70.6)$ & 1.00 \\
\hline Usual solitary sleeper & $35(18.4)$ & $97(21.7)$ & 0.67 (0.30 to 1.48$)$ \\
\hline Usual bed sharer & 37 (19.5) & $34(7.6)$ & 2.66 (1.19 to 5.98$)$ \\
\hline \multicolumn{4}{|c|}{$\begin{array}{l}\text { *Usual room sharer: infants who usually shared parental bedroom but not bed; usual solitary sleeper: } \\
\text { infants who usually slept in room separate from parents either alone or with other siblings; usual bed } \\
\text { sharer: infants who usually shared parental bed for more than two nights/week. } \\
\text { †Adjusted for infant age. } \\
\text { †Socioeconomic classes based on highest occupational classification (I being highest, V being lowest) of } \\
\text { parents and take previous occupation into account (thus unemployed classification comprises households } \\
\text { that have never received waged income). } \\
\text { §For five infants who died and one control infant insufficient information on sleeping environment was } \\
\text { collected to include them in analysis. } \\
\text { १For two infants who died and three control infants socioeconomic class of family could not be accurately } \\
\text { ascertained. }\end{array}$} \\
\hline
\end{tabular}

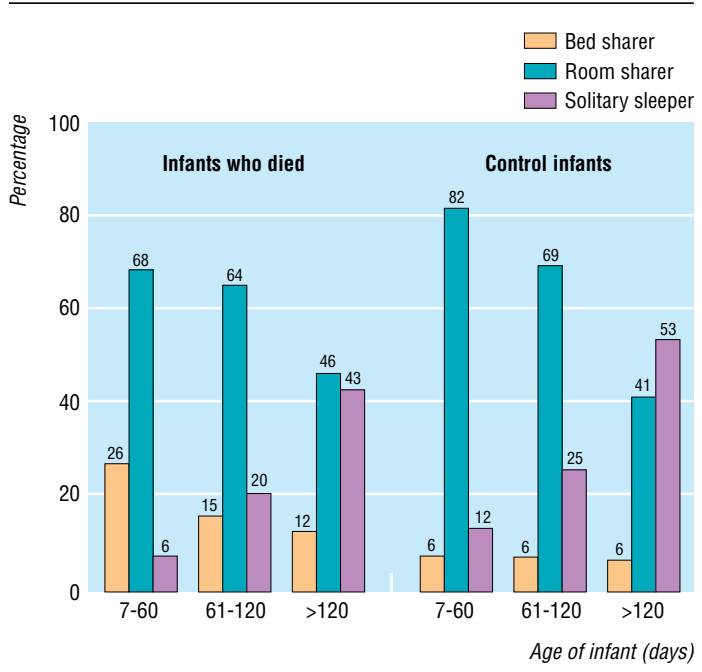

Usual night time sleeping environment by infant age. Numbers of infants: 7-60 days-88 index infants and 352 controls; $61-120$ days -188 and $472 ; \geqslant 120$ days -113 and 452 . Each age band represents third of whole dataset and nearest whole month in age

erence sleep in the 24 hours before the interview. Because of the time lag to arrange four control interviews the control infants were on avereage about 10 days older than the index infants. The variable for infant age was therefore included in all univariate and multivariate analyses. Models were constructed with the backward stepwise procedure for variables significant at the $5 \%$ level in the univariate analysis. When the data were split for analysis (for example, younger and older infants) the four controls were partitioned, regardless of age, into the same subgroup as the corresponding index infant.

\section{Results}

\section{Ascertainment}

In the three year period there were 456 sudden unexpected deaths in infancy, of which 363 were classified as the sudden infant death syndrome. ${ }^{18}$ Of these 363 families, 24 refused an interview and 14 were excluded from the analysis because of police involvement (suspected non-accidental injury), because they lived outside the study regions, or because they could not be traced. Each excluded control family $(7.9 \%)$ was immediately replaced, yielding 325 cases and 1300 controls.

\section{Where the infant slept: usual night time practice}

For all families the most common night time sleeping arrangement was that the infant slept in a cot in the parents' bedroom. Table 1 examines room sharing, solitary sleeping, and bed sharing in relation to social class. Infants who usually shared the parents' bed were at increased risk in this univariate analysis, regardless of the socioeconomic breakdown. The figure shows the same data, dividing infants into three age bands. The difference in the prevalence of bed sharing between infants who died and the control infants was greatest for those aged less than 60 days.

\section{Where the infant slept: last or reference sleep} Table 2 shows the infants' sleeping environment for the last or reference sleep. A greater proportion of index 
infants slept in the same bed or in a separate room from their parents. This breakdown is different from the usual night time practice (table 1), partly because of the broad definition of bed sharing and partly because some of the deaths and matched reference sleeps occurred during the day (54 (16.9\%) deaths and 205 $(15.8 \%)$ controls), when the routine was different. Restriction of the analysis to night time deaths yielded virtually identical results to those detailed here.

Table 3 shows a multicategorical variable that differentiates bed sharers into those infants who shared the bed but were put back in their own cot, those infants who shared the bed either for the whole sleep or were found in the parental bed at the end of the sleep, and those infants who slept on a sofa with a parent. The multivariate model is based on all factors significant in the univariate analysis.

There was no increased risk of death for infants who shared the bed but were put back in their own cot but a significant association with those infants who bed shared for the whole sleep or were taken to and found in the parental bed, infants who slept in a separate room from their parents, and infants who shared a sofa. The strengths of these associations increased dramatically in the multivariate model. Some factors in the multivariate model predominantly involved infants sleeping in a cot rather than the parental bed, such as infants being put down in the prone sleeping position (20.8\% deaths in a $\cot v 2.5 \%$ deaths in a shared bed), placed on a pillow $(11.6 \% \approx 1.2 \%)$, or infants being found with their heads covered $(19.0 \%$ v $6.9 \%)$. Removal of these three variables halved the strength of the association with being found in a shared bed (multivariate odds ratio $4.62 ; 95 \%$ confidence interval 2.34 to 9.09 ). The proportion of index infants found in the prone position was three times higher among infants found in a cot compared with the parental bed $(45.4 \%$ v $14.1 \%)$.

Of those infants found in the parental bed for the last or reference sleep, some parents brought their infants to bed for breast feeding $(14.8 \%$ v $21.2 \%$ controls) or bottle feeding ( $14.8 \% v 7.4 \%)$; more of the index parents did so because they usually slept that way $(44.4 \% v 31.2 \%)$ and more of the control parents because the baby would not settle $(19.8 \% v 30.7 \%)$. Few parents had brought the infant into bed because the baby was unwell $(1.2 \%$ v $3.7 \%)$, because the baby was cold $(1.2 \% v 1.6 \%)$, or for a cuddle and extra time in bed $(3.7 \% v 4.2 \%)$.

A similar proportion of these infants slept with just one parent in the bed (18.9\% $v 17.3 \%)$, almost always the mother. Most infants slept next to one parent $(73.1 \%$ v 63.0\%), but more control infants slept between parents $(22.0 \% v 37.0 \%)$. Two index infants were found under a parent, one was found at the bottom of the bed, and one was found on the floor.

The infants who died in the parental bed (median (interquartile range) age 8 (4-13) weeks) were much younger than those who were found elsewhere (15 (10-23) weeks). When the data were split into younger and older infants by using the median age of all study infants (14 weeks 2 days), the risk associated with bed sharing for older infants found in the parental bed (odds ratio $1.08 ; 95 \%$ confidence interval 0.55 to 2.11 ) was almost unity but for the younger infants the associated risk was significant $(4.65 ; 2.70$ to 7.99$)$.
Table 2 Infant's sleeping environment in relation to parents: last or reference sleep. Figures are numbers (percentage) of babies

\begin{tabular}{lccc} 
Infant details & $\begin{array}{c}\text { Infants who died } \\
(\mathbf{n}=\mathbf{3 2 1})^{*}\end{array}$ & $\begin{array}{c}\text { Controls } \\
(\mathbf{n}=\mathbf{1 2 9 9})^{*}\end{array}$ & Univariate odds ratio† (\%5 $\mathbf{~ I ) ~}$ \\
\hline Room sharer & $81(25.3)$ & $506(39.0)$ & 1.00 \\
\hline Solitary sleeper & $114(35.6)$ & $420(32.3)$ & $1.94(1.33$ to 2.81) \\
\hline Bed sharer $\neq$ & $126(39.4)$ & $373(28.7)$ & $2.00(1.38$ to 2.90) \\
\hline
\end{tabular}

${ }^{*}$ For four infants who died and one control infant insufficient information on sleeping environment was collected to include them in analysis.

tAdjusted for infant age.

flncludes all infants who shared same sleeping place (bed or sofa) with at least one parent for any part of last or reference sleep.

Table 3 Infant's sleeping environment in relation to parents: last or reference sleep. Figures are numbers (percentage) of babies

\begin{tabular}{|c|c|c|c|c|}
\hline Infant details & $\begin{array}{l}\text { Infants who } \\
\text { died }(n=321)\end{array}$ & $\begin{array}{l}\text { Controls } \\
(n=1299)\end{array}$ & $\begin{array}{l}\text { Univariate odds ratio* } \\
(95 \% \mathrm{CI})\end{array}$ & $\begin{array}{l}\text { Multivariate odds } \\
\text { ratio† }(95 \% \mathrm{CI})\end{array}$ \\
\hline Room sharer & $81(25.2)$ & $506(39.0)$ & 1.00 & 1.00 \\
\hline Solitary sleeper & $114(35.5)$ & $420(32.3)$ & $1.92(1.32$ to 2.80$)$ & 10.49 (4.26 to 25.81$)$ \\
\hline $\begin{array}{l}\text { Bed sharer (put back in } \\
\text { own cot) } \ddagger\end{array}$ & $24(7.5)$ & $178(13.7)$ & 0.66 (0.38 to 1.13$)$ & 0.67 (0.22 to 2.00$)$ \\
\hline $\begin{array}{l}\text { Bed sharer (at end of } \\
\text { sleep)§ }\end{array}$ & $82(25.5)$ & $189(14.5)$ & 2.75 (1.85 to 4.08$)$ & 9.78 (4.02 to 23.83$)$ \\
\hline Sofa sharern & $20(6.2)$ & $6(0.5)$ & 31.25 (8.78 to 111.23$)$ & 48.99 (5.04 to 475.60$)$ \\
\hline
\end{tabular}

*Adjusted for infant age.

tControlled for maternal age (continuous variable); parity (including index or control: 1 child $v 2,3$ or 4,5 or more); gestational age ( $\geqslant 39$ weeks $v 37-38$ weeks, $<37$ weeks); birth weight (continuous variable); multiple births (singleton $v$ twin or triplets); unemployment (at least one parent employed $v$ both or single mother unemployed); overcrowding (number of people per room excluding toilet, bathroom, hallway, and kitchen if not dining room ( $<2 v \geqslant 2$ ); maternal smoking during pregnancy (no $v$ yes); paternal smoking (no $v$ yes); paternal drug use (since baby was born: never or only once taken illegal substance $v$ two or more times); daily postnatal exposure to tobacco smoke (parental estimate of hours infant exposed per day: $0 \mathrm{v} 1$ or more hours); previous episode of apparent life threatening event according to parents (none $v 1$ or more); maternal anxiety over infant becoming too hot (not anxious $v$ anxious); infant put down in prone or side position for last sleep (supine $v$ prone, side); infant being found after last sleep with bedcovers over head (no $v$ yes); use of dummy for any part of last sleep (no $v$ yes); use of pillow (no $v$ yes); recent maternal alcohol consumption before last sleep ( $\leqslant 2$ units $v>2$ units); parental estimate of poor health (good or fair $v$ poor); parental tiredness (longest period of infant sleep in previous 24 hours before last sleep ( $>4 v \leqslant 4$ hours); change in routine affecting infant (not at home, having visitors, non-parental carer, etc: no $v$ yes); sleeping under duvet and thickness ( 0 tog $v 1-4$ tog, $5-8$ tog, $\leqslant 9$ tog). All of these factors were significant in multivariate model with exception of last variable, which was just above $5 \%$ significance. $\$ 12$ infants who died and 39 control infants then put back in own room, rest put back in parental bedroom. $\S 54 / 82$ infants who died shared bed for whole sleep compared with 74/189 control infants.

१Two control infants did not share sofa by end of sleep.

The index infants who shared a sofa with a parent (median age 9 weeks; 6 to 15 weeks) were similar in age to those who died in the parental bed. Sofa sharing was as common with mothers as fathers. The narrative account suggests that for four deaths the infant was wedged between the parent and the back of the sofa, while for five the parent and infant lay at opposite ends, although we do not have data on the size of the sofa or the position of the adult's legs. Seven of the index parents had not intended to fall asleep on the sofa, but for nine this practice was not unusual. In five of these deaths the cosleeping parent had consumed up to 2 units of alcohol, and three had consumed much more than this.

\section{Associated risks}

Table 4 examines the relation between parental smoking and infants found bed sharing. The proportion of index infants found dead in bed with parents who did not smoke was much lower than for control families who did not smoke (2.2\% $v 7.9 \%$ controls). The high prevalence of smoking among index parents $(84.2 \%)$ was even higher among those parents whose infant was found in the parental bed at the end of the last or reference sleep (91.4\%). Among index mothers who smoked, more of those whose infants shared the bed smoked more than 20 cigarettes a day $(23.2 \% v 1.5 \%$ controls) compared with those who did not bed share $(16.6 \% v 5.9 \%)$. 
Table 4 Infants found bed sharing at end of sleep and parental smoking. Figures are numbers (percentage) of infants unless stated otherwise

\begin{tabular}{lcccc}
$\begin{array}{l}\text { At least one parent } \\
\text { smokes* }\end{array}$ & $\begin{array}{c}\text { Infant found } \\
\text { bed sharing }\end{array}$ & $\begin{array}{c}\text { Infants who died } \\
(\mathbf{n}=\mathbf{3 2 1})\end{array}$ & $\begin{array}{c}\text { Controls } \\
(\mathbf{n = 1 2 9 9 )}\end{array}$ & $\begin{array}{c}\text { Univariate odds ratio† } \\
\text { (95\% CI) }\end{array}$ \\
\hline No & No & $44(13.7)$ & $582(44.8)$ & 1.00 \\
\hline No & Yes & $7(2.2)$ & $103(7.9)$ & $1.08(0.45$ to 2.58) \\
\hline Yes & No & $195(60.7)$ & $528(40.6)$ & $5.34(3.61$ to 7.90$)$ \\
\hline Yes & Yes & $75(23.4)$ & $86(6.6)$ & $12.35(7.41$ to 20.59) \\
\hline
\end{tabular}

*Mother or partner at time of interview.

tAdjusted for infant age.

Table 5 Multivariate model controlling for adverse bed sharing conditions. Figures are numbers (percentage) of infants unless stated otherwise

\begin{tabular}{lcccc} 
Details for infant* & $\begin{array}{c}\text { Infants who } \\
\text { died }(\mathbf{n}=\mathbf{3 1 2})\end{array}$ & $\begin{array}{c}\text { Controls } \\
\mathbf{( n = 1 2 9 5 )}\end{array}$ & $\begin{array}{c}\text { Multivariate odds ratio } \\
\mathbf{( 9 5 \% ~} \mathbf{C I})\end{array}$ & P value \\
\hline Solitary sleeper & $111(35.6)$ & $419(32.4)$ & $1.96(1.31$ to 2.93$)$ & 0.001 \\
\hline Bed sharer (put back in cot) & $24(7.7)$ & $178(13.7)$ & $0.60(0.33$ to 1.08$)$ & 0.09 \\
\hline Bed sharer (at end of sleep) & $79(25.3)$ & $186(14.4)$ & $1.35(0.83$ to 2.20$)$ & 0.23 \\
\hline Sofa sharer & $20(6.4)$ & $6(0.5)$ & $25.86(6.72$ to 99.47$)$ & $<0.0001$ \\
\hline Parental tiredness† & $86(27.6)$ & $191(14.7)$ & $2.42(1.61$ to 3.63$)$ & $<0.0001$ \\
\hline Maternal alcohol consumption $\neq$ & $37(11.9)$ & $41(3.2)$ & $3.40(1.88$ to 6.16$)$ & $<0.0001$ \\
\hline Overcrowding§ & $13(4.2)$ & $4(0.3)$ & $18.49(3.62$ to 94.48$)$ & 0.0005 \\
\hline Duvet tog: & & & & \\
\hline $1-4$ & $37(11.9)$ & $139(10.7)$ & $1.47(0.90$ to 2.39$)$ & 0.12 \\
\hline $5-8$ & $59(18.9)$ & $91(7.0)$ & $3.97(2.43$ to 6.46$)$ & $<0.0001$ \\
\hline$\geqslant 9$ & $26(8.3)$ & $32(2.5)$ & $3.26(1.54$ to 6.90$)$ & 0.002 \\
\hline
\end{tabular}

* Reference group for sleeping environment (first four variables) was infants who shared room, reference group for duvet thickness (last three variables) was infants who did not use duvet.

† Defined as longest period of infant sleep in previous 24 hours before last sleep: $>4 v \leqslant 4$ hours).

$\ddagger>2$ units of alcohol in 24 hours before last or reference sleep.

$\S$ Defined as $>2$ people per room (excluding kitchen not used for dining, toilet, bathroom, and hallways).

The multivariate analysis suggests that there are some variables for which the risk is exclusively associated with the cot environment yet increase the significance of the risk associated with the bed sharing environment. Table 5 shows the more restricted model of factors that were predominantly associated with being found in the parental bed after the last or reference sleep. These included recent maternal alcohol consumption of more than 2 units $(21.0 \%$ deaths in a shared bed $v 8.6 \%$ deaths in a cot), infants covered by a duvet $(61.0 \%$ $v 31.9 \%$ ), parental tiredness ( $54.6 \%$ v 20.3\%), and sleeping environments in overcrowded conditions $(8.5 \% v$ $2.5 \%$ ). Individually each of these variables reduced the significance of the risk associated with bed sharing, and when all were put into a collective model, being found in a shared bed was no longer significant.

\section{Discussion}

\section{Study findings}

Our results show that infants sharing a sofa with an adult during sleep is associated with a particularly high and previously unrecognised risk of the sudden infant death syndrome. The apparent risk associated with infants sleeping in a separate room from the parents and sharing a bed for the whole or last part of sleep is less clear because of potential confounding. We found no increase in risk for older infants who share the parents' bed, infants of parents who do not smoke, or when the infant is returned to his or her cot. In the more restricted model, which incorporated factors for which there was an a priori expectation of their potential effects on the sleep environment, the independent significance of sharing the bed at the end of sleep disappeared. This result suggests that the risk of death may be associated with other potentially modifiable adverse conditions rather than the practice of bed sharing itself, although interpretation should be cautious given the prior expectation of this particular analysis.

The increased relative risk of death among infants who sleep in a separate room, regardless of infant age or risks associated with the cot environment, is consistent with the findings of the New Zealand study, ${ }^{21}$ although for a third of both cases and controls, this was a day time practice and not necessarily the night time routine. Cosleeping in terms of room sharing increases the sensory exchanges possible between parent and infants, ${ }^{22}$ but further research is required to investigate whether room sharing is protective in itself or merely a marker for hidden confounders not measured in this study.

\section{Problems with interpretation}

Our results highlight some of the methodological difficulties inherent in multivariate modelling. In the large multivariate model the infant who was found sharing the bed at the end of the sleep seemed to be an important risk factor. Within this model, however, it was difficult to quantify the strength of the risk given that the interaction of certain cofactors was based on the environment in which the infant slept; nor is it possible to generalise these multivariate findings to the whole population. Certain factors characteristic of infants found in the parental bed were systematically different from those where the infant was found in a cot: bed sharing infants were much younger, few were put down in the prone position, and few were found with their heads covered. Conversely these factors were reversed among infants who slept separately from their parents.

The high prevalence of smokers among the bed sharing parents of infants who died confirms the findings of Mitchell ${ }^{21}$ and makes it impossible to derive precise estimates of the risk associated with bed sharing for families who do not smoke.

\section{Informed evidence}

The practices of sharing the bed and cosleeping are culturally diverse. For example, a baby sleeping at arm's length from the mother on a firm surface, as is often the case in Hong Kong, ${ }^{23}$ or a Pacific Island baby sleeping on the bed rather than in the bed ${ }^{21}$ is in a different environment from a baby sleeping in direct contact with the mother on a soft mattress and covered by a thick duvet. Previous observational studies have highlighted contributory factors such as parental alcohol consumption, parental fatigue, a lack of an alternative sleeping place, and the use of thick duvets ${ }^{10-12}$; our data have extended these observations and given quantitative estimates of the relative risks for these factors.

Unlike cots, which are designed to meet safety standards for infants, adult beds are not so designed and may, at least in theory, carry a risk of accidental entrapment and suffocation. This and the conflicting evidence for harm or benefit from bed sharing shown in previous studies have generated strong professional beliefs about the appropriateness or otherwise of sharing a bed and cosleeping.

The debate on the safety, advantages, and disadvantages of bed sharing and cosleeping must be informed by evidence from epidemiology, physiology, and anthropology if it is to become more than the exchange of mere opinion. There has been little in the way of direct observational data until recently, but it is 
becoming clear that sharing a bed both for infants and mothers results in complex interactions that are completely different from isolated sleeping and that need to be understood in detail before application of simplistic labels such as "safe" or "unsafe."24 25 Our results suggest that, as McKenna has argued, perhaps it is not bed sharing per se that is hazardous but rather the particular circumstances in which bed sharing occurs. That some of these circumstances may be modifiable has important implications in terms of social policy and health education.

Contributors: PSB, PJF, IJS, MWP, PJB, and JG were all involved in the concepts and design from the beginning of the study. The analysis was conducted by PSB under the supervision of the others, and all were involved in the interpretations of the data, drafting, and revisions. PSB, PJF, and IJS supervised data collection for the whole study period within their particular regions. MWP supervised data collection for the final year of the study. PJB supervised collection of postmortem samples and data from all the regions. JG provided epidemiological advice. JY, a research nurse who runs the sleep laboratory in Bristol, and Pam Nadin, a research health visitor, were involved in the interpretation of the data and subsequent analyses, drafting, and revisions of this paper. PJF is the guarantor for the study.

Funding: The National Advisory Body for CESDI and the Foundation for the Study of Infant Deaths.

Competing interests: None declared.

1 Mosko S, McKenna J, Dickel M, Hunt L. Parent-infant co-sleeping: the appropriate context for the study of infant sleep and implications for sudden infant death syndrome (SIDS) research. I Behav Med sudden infant ceat

2 Anderson GC. Current knowledge about skin-to-skin (kangaroo) care for preterm infants. J Perinatol 1991;11:216-26.

3 Ludington-Hoe SM, Hadeed AJ, Anderson GC. Physiological responses to skin-to-skin contact in hospitalised premature infants. $J$ Perinatol 1991:11:19-24.

4 Luke JL. Sleeping arrangements of sudden infant death syndrome victims in the District of Columbia-a preliminary report. J Forensic Sci 1978;23:379-83.

5 Klonoff-Cohen HS, Edelstein SL. Bed sharing and the sudden infant death syndrome. $B M J$ 1995;311:1269-72.

6 Lee NNY, Chan YF, Davis DP, Lau E, Yip DCP. Sudden infant death syndrome in Hong Kong: confirmation of a low incidence. $B M$ J 1989;298:721-2.

7 Carpenter RG. Sudden and unexpected deaths in infancy (cot death). In: Camps FE, Carpenter RG, eds. Sudden and unexpected deaths in infancy (cot death). Bristol: John Wright, 1972:7-15.

8 Bass M, Kravath RE, Glass LG. Death-scene investigation in sudden infan death. N Engl J Med 1986;315:100-5

9 Rintahaka PJ, Hirvonen J. The epidemiology of sudden infant death syndrome in Finland in 1969-80. Forens Sci Int 1986;30:219-33.

10 Mitchell EA, Taylor BJ, Ford RPK, Stewart AW, Becroft DM, Thompson

$\mathrm{JM}$, et al. Four modifiable and other major risk factors for cot death: the New Zealand study. NJ Paediatr Child Health 1992;28:1:3-S8.

11 Mitchell EA, Stewart AW, Scragg R, Ford RPK, Taylor BJ, Becroft DMO, et al. Ethnic differences in mortality from sudden infant death syndrome in New Zealand. BMJ 1993;306:13-6.
Key messsages

- Cosleeping with an infant on a sofa was associated with a particularly high risk of sudden infant death syndrome

- Sharing a room with the parents was associated with a lower risk

- There was no increased risk associated with bed sharing when the infant was placed back in his or her cot

- Among parents who do not smoke or infants older than 14 weeks there was no association between infants being found in the parental bed and an increased risk of sudden infant death syndrome

- The risk linked with bed sharing among younger infants seems to be associated with recent parental consumption of alcohol, overcrowded housing conditions, extreme parental tiredness, and the infant being under a duvet

12 Hoffman HJ, Hunter JC, Ellish NJ, Janerich DT, Goldberg J. Adverse reproductive factors and the sudden infant death syndrome. In: Harper RM, Hoffman HJ, eds. Sudden infant death syndrome. Risk factors and basic mechanisms. New York: PMA Publishing, 1988:153-75.

13 Takeda KA. A possible mechanism of sudden infant death syndrome (SIDS).J Kyoto Prefecture University Med 1987;96:965-8.

14 Davies DP. Cot death in Hong Kong. A rare problem? Lancet 1985;ii:1346-7.

15 Gantley M, Davies DP, Murcott A. Sudden infant death syndrome. Links with infant care practices. BMJ 1993;16:263-22.

16 Farooqi S, Lip GYH, Beevers DG. Bed sharing and smoking in sudden infant death syndrome. BMJ 1994;308:204-5.

17 Tuohy PG, Counsell AM, Geddis DC. Sociodemographic factors associated with sleeping position and location. Arch Dis Child 1993:69:664-6.

18 Leach CEA, Blair PS, Fleming PJ, Smith IJ, Ward Platt M, Berry PJ, et al. Sudden unexpected deaths in infancy: similarities and differences in the epidemiology of SIDS and explained deaths. Pediatrics (in press).

19 Fleming PJ, Blair PS, Bacon C, Bensley D, Smith I, Taylor E, et al. Environment of infants during sleep and risk of sudden infant death syndrome: results of 1993-5 case-control study for confidential inquiry into stillbirths and deaths in infancy. BMJ 1996;313:191-5.

20 SAS Institute. SAS technical report P-229, SAS/STAT software: changes and enhancements, release 6.07. Cary, NC: SAS Institute, 1992.

21 Mitchell EA, Thompson JMD. Co-sleeping increases the risk of SIDS, but sleeping in the parents' bedroom lowers it. In: TO Rognum, ed. Sudden infant death syndrome. New trends in the nineties. Oslo: Scandanavian University Press, 1995

22 McKenna J, Mosko S, Richard C, Drummond S, Hunt L, Cetel MB, et al. Experimental studies of infant-parent co-sleeping: mutual physiological and behavioural influences and their relevance to SIDS (sudden infant death syndrome). Early Hum Dev 1994;38:187-201.

23 Nelson EAS, Chan PH. Child care practices and cot death in Hong Kong. N Z Med J 1996;109:144-6.

24 McKenna. Sudden infant death syndrome in cross-cultural perspective. Is infant-parent cosleeping protective? Ann Rev Anthropol 1996;25:201-16.

25 Ball HL, Hooker E, Kelly PJ. Where will the babies sleep? Attitudes and practices of new and experienced parents regarding co-sleeping with their new- born infant. Am Anthropol (in press).

(Accepted 24 August 1999)

\section{Commentary: Cot death-the story so far}

Ed Mitchell

Mortality from the sudden infant death syndrome dropped dramatically in the late 1980s and early 1990s in most developed countries. This was attributed to the change in sleep position after the "Back to Sleep" campaign, which advised parents not to place their baby to sleep on their front. More recent work suggests that the back is the preferred sleeping position as the side sleeping position is unstable and infants may turn on to their front. ${ }^{1}$ Healthy infants are not at increased risk of aspiration if placed to sleep on their back.
This observation showed that the syndrome, although still unexpected, was no longer nonpreventable. Many other pieces of advice have been given, some with strong evidence but others with no or limited support. This commentary provides a brief personal view as to what we currently know about effective prevention.

Most countries have also included avoidance of tobacco smoking as part of their prevention advice. A recent meta-analysis has found that infants of mothers
Department of Paediatrics, Faculty of Medicine and Health Sciences, University of Auckland, Postbag 92019, Auckland, New Zealand Ed Mitchell associate professor in paediatrics

ed.mitchell@ auckland.ac.nz 
who smoked in pregnancy are at almost a fivefold increased risk of the sudden infant death syndrome compared with infants of non-smokers. ${ }^{2}$ The effect of environmental exposure to tobacco smoke is less clear. A meta-analysis of studies in which the mother did not smoke but the father did found the risk was increased 1.4-fold compared with non-smoking parents. ${ }^{2}$ Now that few infants sleep prone maternal smoking is the major risk factor. The challenge is to develop effective strategies to reduce smoking in pregnancy as simply telling mothers that their babies are at increased risk of the sudden infant death syndrome is ineffective at changing behaviour.

Thermal stress has been implicated and has led to the advice not to let baby get too hot. Recent work suggests that excessive clothing or bedding increases the risk only in infants who sleep prone. Infants are at increased risk of thermal stress when sleeping prone because the face, which is the most important skin surface for heat loss, is partially insulated by the mattress. ${ }^{3}$ Thermal factors are no longer important as few babies sleep prone; head covering and rebreathing are alternative, more likely explanations for the finding of an increased risk for babies sleeping under heavy duvets.

Other prevention messages have been promoted but with less agreement. Breast feeding is thought to reduce the risk in New Zealand, but in the United Kingdom the association is attributed to socioeconomic confounding. Pacifiers (dummies) are associated with a reduced risk, and their use is promoted in the
Netherlands, ${ }^{4}$ whereas in other countries there is concern that their use might be associated with undesirable effects, such as reduction in breast feeding. ${ }^{5}$

In this paper Blair et al have shown that infants who share a sofa with an adult were at particularly high risk of the sudden infant death syndrome, but it accounts for only $6 \%$ of all cases. There was no increased risk with bed sharing for infants of mothers who were non-smokers. Also there was no increased risk associated with bed sharing when the infant was placed back in his or her cot, but this ignores the fact that many parents unintentionally fall asleep with their baby in their bed. In contrast $23 \%$ of deaths in their study occurred among cosleeping infants of mothers who smoke. This confirms work from New Zealand, United States, Scotland, and Nordic countries. ${ }^{1}$ It is time to recommend that mothers who smoke should not share a bed with their babies.

Scragg RKR, Mitchell EA. Side sleeping position and bed sharing in the sudden infant death syndrome. Ann Med 1998;30:345-9.

2 Mitchell EA, Milerad J. Smoking and sudden infant death syndrome. In: Tobacco Free Initiative. International consultation on environmental tobacco smoke (ETS) and child health. Geneva: World Health Organisation, 1999:105-29.

3 Nelson EA, Taylor BJ, Weatherall IL. Sleeping position and infant bedding may predispose to hyperthermia and the sudden infant death syndrome. Lancet 1989;i:199-201

4 L'Hoir MP, Engelberts AC, van Well GThJ, McClelland S, Westers P, Danachli $\mathrm{T}$, et al. Risk and preventive factors for cot death in the Netherlands, a low-incidence country. Eur J Pediatr 1998;157:681-8.

5 Fleming PJ, Blair PS, Pollard K, Platt MW. Leach C, Smith I, et al. Pacifier use and sudden infant death syndrome: results from the CESDI/SUDI case control study. Arch Dis Child 1999;81:112-6.

\title{
Increase in congenital rubella occurrence after immunisation in Greece: retrospective survey and systematic review
}

\author{
Takis Panagiotopoulos, Ioanna Antoniadou, Eleni Valassi-Adam
}

\section{Editorial by King \\ Correspondence to: T Panagiotopoulos tpan@ath.forthnet.gr \\ continued over}

BMJ 1999;319:1462-7

website

extra

Details and references of the trials appear on the BMJ's website

www.bmj.com

\section{Abstract}

Objective To describe the events leading to the epidemic of congenital rubella syndrome in Greece in 1993 after a major rubella epidemic.

Design Retrospective survey and systematic review. Setting Greece (population 10 million), 1950-95. Subjects Children, adolescents, and women of childbearing age.

Results Around 1975 in Greece the measles, mumps, and rubella vaccine started being given to boys and girls aged 1 year without policies to attain high vaccination coverage and to protect adolescents and young women. During the 1980 s, vaccination coverage for rubella remained consistently below $50 \%$, and the proportion of pregnant women susceptible to rubella gradually increased. In 1993 the incidence of rubella in young adults was higher than in any previous epidemic year. The epidemic of congenital rubella that followed, with 25 serologically confirmed cases (24.6 per 100000 live births), was probably the largest such epidemic in Greece after 1950.
Conclusions With low vaccination coverage, the immunisation of boys and girls aged 1 year against rubella carries the theoretical risk of increasing the occurrence of congenital rubella. This phenomenon, which has not been previously reported, occurred in Greece.

\section{Introduction}

Rubella is usually a mild disease, but infection during the first 3-4 months of pregnancy can result in spontaneous abortion, stillbirth, and congenital rubella syndrome. $^{12}$

Immunisation programmes to prevent congenital rubella syndrome were introduced in many countries soon after vaccines for rubella and measles, mumps, and rubella became available in 1969 and 1971 respectively. ${ }^{3}$ The immunisation of boys and girls aged 1 year ("indirect" strategy) aims to protect women of childbearing age from exposure to the rubella virus by interrupting its transmission. ${ }^{45}$ This can lead to a rapid reduction in cases of congenital rubella, but if vaccina- 